\title{
Creative Mathematics Hands-on Activities in the Classroom
}

\author{
Janchai Yingprayoon
}

Many children find mathematics difficult and boring. But they are curious and they love to have fun with exciting things around them. Appropriate activities can be found to stimulate them to have fun and love learning mathematics. The workshop showed ways of developing creativity in mathematics and technology education to increase intellectual curiosity, develop problem-solving and thinking skills, promote discovery, and unleash creativity. There were five activities in the workshop.

\section{Curves in Nature}

A picture of a real bamboo stem and a sheet of graph paper were given to participants to find the relation between two variables using curves. The relation between the sectors of bamboo tree and their lengths were studied and discussed.

\section{Reaction Time Test}

From the given materials, participants studied the nature of a free-falling object by measuring reaction time. The plot between reaction time and the number of participants with that reaction time (frequency) was studied. The distribution plot tends to be a normal distribution.

J. Yingprayoon ( $\square)$

International College, Suan Sunandha Rajabhat University, Bangkok, Thailand

e-mail: janchai@loxinfo.co.th

(C) The Author(s) 2017 


\section{Simple Balance}

The participants made their own simple balance from given materials. They learned about the principle of moment and how to calibrate their scales and calculate error in the measurement. The mathematic relation was discussed.

\section{Mathematics of Robot Arms}

A simple robot arm will be constructed using ice cream sticks. The learners worked on finding the mathematic relations of extended lengths of a robot arm.

\section{Augmented Reality (AR) in Mathematics Education}

This workshop described how to develop a simple AR system for learning mathematics. Sample AR materials used for mathematics education in high school and at the university level were discussed. The workshop showed how to generate and view geometrical objects in three dimensions using mobile phones or computer tablets in order to better understand their mathematical structures.

Open Access Except where otherwise noted, this chapter is licensed under a Creative Commons Attribution 4.0 International License. To view a copy of this license, visit http://creativecommons. org/licenses/by/4.0/.

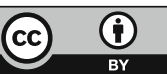

